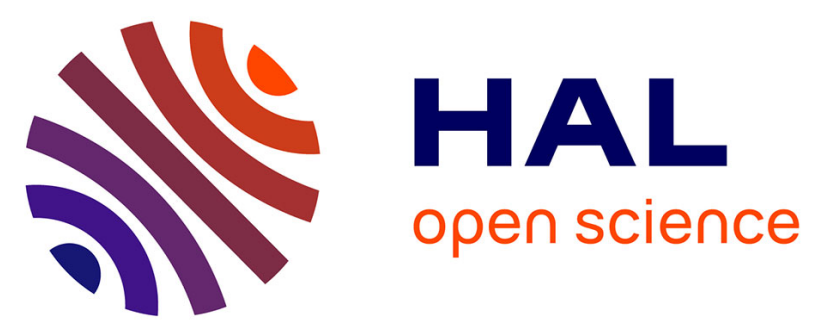

\title{
Electrochemical behavior of high performance on-chip porous carbon films for micro-supercapacitors applications in organic electrolytes
}

Kevin Brousse, Peihua Huang, Sébastien Pinaud, Marc Respaud, Barbara Daffos, Bruno Chaudret, Christophe Lethien, Pierre-Louis Taberna, Patrice Simon

\section{To cite this version:}

Kevin Brousse, Peihua Huang, Sébastien Pinaud, Marc Respaud, Barbara Daffos, et al.. Electrochemical behavior of high performance on-chip porous carbon films for micro-supercapacitors applications in organic electrolytes. Journal of Power Sources, 2016, vol. 328, pp. 520-526. 10.1016/j.jpowsour.2016.08.017 . hal-01466193

\section{HAL Id: hal-01466193 https://hal.science/hal-01466193}

Submitted on 13 Feb 2017

HAL is a multi-disciplinary open access archive for the deposit and dissemination of scientific research documents, whether they are published or not. The documents may come from teaching and research institutions in France or abroad, or from public or private research centers.
L'archive ouverte pluridisciplinaire HAL, est destinée au dépôt et à la diffusion de documents scientifiques de niveau recherche, publiés ou non, émanant des établissements d'enseignement et de recherche français ou étrangers, des laboratoires publics ou privés. 


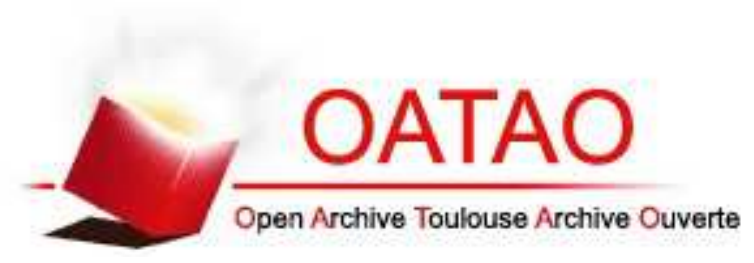

\section{Open Archive TOULOUSE Archive Ouverte (OATAO)}

OATAO is an open access repository that collects the work of Toulouse researchers and makes it freely available over the web where possible.

This is an author-deposited version published in : http://oatao.univ-toulouse.fr/ Eprints ID : 16650

To link to this article : DOI:10.1016/j.jpowsour.2016.08.017

URL : http://dx.doi.org/10.1016/j.jpowsour.2016.08.017

To cite this version : Brousse, Kevin and Huang, Peihua and Pinaud, Sébastien and Respaud, Marc and Daffos, Barbara and Chaudret, Bruno and Lethien, Christophe and Taberna, Pierre-Louis and Simon, Patrice Electrochemical behavior of high performance onchip porous carbon films for micro-supercapacitors applications in organic electrolytes. (2016) Journal of Power Sources, vol. 328. pp. 520-526. ISSN 0378-7753

Any correspondence concerning this service should be sent to the repository administrator: staff-oatao@ listes-diff.inp-toulouse.fr 


\title{
Electrochemical behavior of high performance on-chip porous carbon films for micro-supercapacitors applications in organic electrolytes
}

\author{
K. Brousse ${ }^{\text {a, b }}$, P. Huang a, b, S. Pinaud ${ }^{\text {c }}$, M. Respaud ${ }^{\text {c, d }}$, B. Daffos ${ }^{\text {a, b }}$, B. Chaudret ${ }^{\text {, }}$, \\ C. Lethien ${ }^{\text {b, e }}$, P.L. Taberna ${ }^{\text {a, b }}$, P. Simon ${ }^{\text {a, b, * }}$ \\ a Centre Inter-universitaire de Recherche et d'Ingénierie des Matériaux (CIRIMAT), UMR CNRS 5085, UPS, 118 Route de Narbonne, 31062 Toulouse Cedex 09, \\ France \\ ${ }^{\mathrm{b}}$ Réseau sur le Stockage Electrochimique de l'Energie, FR CNRS n³459, France \\ ${ }^{\mathrm{c}}$ Laboratoire de Physique et Chimie des Nano-Objets (LPCNO), UMR 5215 Institu National des Sciences Appliquées (INSA)-Université Paul Sabatier \\ (UPS)-CNRS, Université de Toulouse, 135 Avenue de Rangueil, 31077 Toulouse, France \\ ${ }^{\mathrm{d}}$ Atelier Interuniversitaire de Micro-nano Électronique (AIME), Université de Toulouse, INSA, UPS, INP, 135 avenue de Rangueil, 31077 Toulouse Cedex 4, \\ France \\ e Université Lille 1 Sciences et Technologies, Laboratoire Institut d'Electronique de Microélectronique et de Nanotechnologie (IEMN), UMR CNRS 8520, \\ Cité scientifique, Avenue Henri Poincaré, CS 60069, 59652 Villeneuve d'Ascq Cedex, France
}

\section{H I G H L I G H T S}

- On-chip CDC films were prepared with different pore sizes and thicknesses.

- Capacitance of $169 \mathrm{~F} \mathrm{~cm}^{-3}$ was achieved in either ACN- or PC-based electrolytes.

- $\mathrm{EMI}^{+}$transport limitation occurred for thicker films in more viscous $2 \mathrm{M} \mathrm{EMIBF}_{4} / \mathrm{PC}$

- High energy density was obtained for $7 \mu$ m-thick CDC films in $2 \mathrm{M} \mathrm{EMIBF}_{4} / \mathrm{ACN}$.

Keywords:

Micro-supercapacitors

Carbide derived carbon

Electrochemical behavior

Non-aqueous electrolytes

\section{A B S T R A C T}

Carbide derived carbons (CDCs) are promising materials for preparing integrated micro-supercapacitors, as on-chip CDC films are prepared via a process fully compatible with current silicon-based device technology. These films show good adherence on the substrate and high capacitance thanks to their unique nanoporous structure which can be fine-tuned by adjusting the synthesis parameters during chlorination of the metallic carbide precursor. The carbon porosity is mostly related to the synthesis temperature whereas the thickness of the films depends on the chlorination duration. Increasing the pore size allows the adsorption of large solvated ions from organic electrolytes and leads to higher energy densities. Here, we investigated the electrochemical behavior and performance of on-chip TiC$\mathrm{CDC}$ in ionic liquid solvent mixtures of 1-ethyl-3-methylimidazolium tetrafluoroborate (EMIBF 4 ) diluted in either acetonitrile or propylene carbonate via cyclic voltammetry and electrochemical impedance spectroscopy. Thin CDC films exhibited typical capacitive signature and achieved $169 \mathrm{~F} \mathrm{~cm}^{-3}$ in both electrolytes; $65 \%$ of the capacitance was still delivered at $1 \mathrm{~V} \mathrm{~s}^{-1}$. While increasing the thickness of the films, $\mathrm{EMI}^{+}$transport limitation was observed in more viscous PC-based electrolyte. Nevertheless, the energy density reached $90 \mu \mathrm{W} \mathrm{h} \mathrm{cm}{ }^{-2}$ in $2 \mathrm{M} \mathrm{EMIBF}_{4} / \mathrm{ACN}$, confirming the interest of these CDC films for micro-supercapacitors applications.

\footnotetext{
* Corresponding author. Centre Inter-universitaire de Recherche et d'Ingénierie des Matériaux (CIRIMAT), UMR CNRS 5085, UPS, 118 Route de Narbonne, 31062 Toulouse Cedex 09, France.

E-mail address: simon@chimie.ups-tlse.fr (P. Simon).
}

\section{Introduction}

The myriad of portable electronic devices brings new needs in terms of mobility and autonomy, such as high performance miniaturized energy storage systems. While batteries are used for energy delivery, they still suffer from limited power capabilities and 
cyclability, owing to the faradic nature of the electrochemical storage process.

Electrochemical double-layer capacitors (EDLCs), also called supercapacitors, store energy via reversible adsorption of ions from an electrolyte which is a fast non-faradic process, leading to high power densities and very long cycle life (more than 1,000,000 cycles) $[1,2]$. Therefore, this technology has already been used in broad range of applications in power electronics such as power buffer or memory back-up for toys, cameras, or mobile phones $[1,3,4]$. EDLCs are also used in transportation to recover braking energy in tramways, hybrid electric vehicles and buses [1,5].

Among various active materials, carbide derived carbons (CDCs) have spawned much interest as they offer a unique pore size and pore size distribution control by selectively etching metal atoms from carbide powders, ceramics, felts and so on [6-13]. They demonstrated great performances as their pore diameter was adapted to the ion size, leading to important capacitance gains $[14,15]$. These materials can even compete with pseudocapacitive materials which deliver larger capacitance [16-19] but show a decrease in power capabilities because of the faradic reactions kinetics $[18,20]$.

CDC powders have been widely studied in tetraalkylammonium tetrafluoroborate based electrolytes in acetonitrile (ACN) [8,21,22], propylene carbonate (PC) or $\gamma$-butyrolactone [23], as well as in ionic liquids such as 1-ethyl-3-methylimidazolium tetrafluoroborate [24-26] and 1-ethyl-3-methylimidazolium bis(trifluoromethanesulfonyl)imide [27]. Unfortunately, mixing high specific surface area carbon powders with a binder to prepare film electrodes does not fit with the requirements of the semiconductor industry, where thickness control and good adherence on silicon chips are needed. To overcome this technological barrier, $\mathrm{CDC}$ began to be synthesized from the chlorination of metal carbide films sputtered by physical vapor deposition technique [28], allowing the direct integration of CDC films on silicon wafers to prepare micro-supercapacitors [29,30]. These on-chip CDC films showed very good adherence with rubber-like mechanical properties and delivered very high capacitance of $410 \mathrm{~F} \mathrm{~cm}^{-3}$ in $1 \mathrm{M}$ $\mathrm{H}_{2} \mathrm{SO}_{4}$ and $160 \mathrm{~F} \mathrm{~cm}^{-3}$ in $2 \mathrm{M} \mathrm{EMIBF}_{4}$ in $\mathrm{ACN}$ [31]. However, so far, no studies have addressed the influence of $\mathrm{CDC}$ films structure and texture on the electrochemical behavior in various electrolytes. This work investigates the electrochemical behavior and performance of on-chip micrometer-thick TiC-CDC in $\mathrm{EMIBF}_{4}$ diluted in either acetonitrile or propylene carbonate for micro-supercapacitors applications.

\section{Experimental}

\subsection{Material preparation}

TiC films were deposited by using a non-reactive direct current magnetron sputtering technique (DC-MS) on $\mathrm{Si} / \mathrm{SiO}_{2}$ wafers. A TiC target (99.5\%, $10 \mathrm{~cm}$ diameter, $6 \mathrm{~mm}$ thick) was sputtered under argon atmosphere in the DP 650 sputtering equipment (Alliance Concept) under $0.01 \mathrm{mbar}$ at $750{ }^{\circ} \mathrm{C}$ as described in previous work [31]. The power density was kept at $2 \mathrm{~W} \mathrm{~cm}^{-2}$ during the sputtering deposition. The thickness of the sputtered TiC thin films is controlled by the deposition time. Then the deposited TiC was placed in a furnace under argon purge. When the desired temperature was reached, the titanium carbide was converted to TiC-CDC by reacting with chlorine gas as described below (1):

$$
\mathrm{TiC}+2 \mathrm{Cl}_{2} \rightarrow \mathrm{TiCl}_{4}+\mathrm{C}
$$

The chlorination time was carefully controlled to perform partial chlorination and obtain a CDC film strongly bonded to a residual conductive TiC layer underneath [31].

Chlorination temperatures of $450^{\circ} \mathrm{C}$ and $700{ }^{\circ} \mathrm{C}$ were selected to prepare CDC films with different structure (pore size and pore size distribution). On-chip CDC films of more than $1 \mathrm{~cm}^{2}$ were obtained (Fig. 1A). The structure of the $\mathrm{TiC}$ precursor is preserved after conversion into $\mathrm{CDC}$ for both $450{ }^{\circ} \mathrm{C}$ (Fig. $1 \mathrm{~B}$ and C) and $700^{\circ} \mathrm{C}$ (Fig. 1D and E) chlorination temperatures, with continuous columnar structure [31]. Cooling down was done under argon and further annealing was performed at $600^{\circ} \mathrm{C}$ under $\mathrm{H}_{2}$ atmosphere to remove residual chlorine species trapped into the nanopores [10].

\subsection{Structural and electrochemical characterization}

Raman spectra of the chlorinated CDC films were recorded using a Raman spectrometer LabRAM HR (Horiba Yvon-Joblin, $514 \mathrm{~nm}$ wavelength).

Gas sorption experiments were achieved on self-supported CDC films fully chlorinated at the desired temperatures and placed in a BELSORP-mini II (BEL, Japan) apparatus. The $\mathrm{Ar}$ and $\mathrm{CO}_{2}$ adsorption isotherms were used to estimate the Brunauer-Emmett-Teller (BET) surfaces and the pore size distributions.

The electrochemical characterizations of the $\mathrm{Si} / \mathrm{SiO}_{2} / \mathrm{TiC} / \mathrm{CDC}$ were conducted using a Biologic VMP3 Potentiostat in $2 \mathrm{M} \mathrm{EMIBF}_{4}$ either in acetonitrile or propylene carbonate (conductivities of $60 \mathrm{mS} \mathrm{cm}^{-1}$ and $17 \mathrm{mS} \mathrm{cm}^{-1}$ in ACN and PC, respectively) [32] in a three-electrode configuration. All experiments were carried out at room temperature under $\mathrm{Ar}$ atmosphere $\mathrm{O}_{2}$ and $\mathrm{H}_{2} \mathrm{O}$ contents lower than $0.1 \mathrm{ppm})$. A silver wire was used as quasi-reference and a Pt foil as counter electrode. Electrochemical impedance spectroscopy (EIS) measurements were conducted on the freshly assembled cells by applying a $5.0 \mathrm{mV}_{\mathrm{RMS}}$ sinusoidal signal amplitude from $100 \mathrm{kHz}$ to $10 \mathrm{mHz}$ at the open circuit potential, and cyclic voltammetry was performed at several scan rates.

The electrolyte viscosities were measured with a MCR 301 Rheometer (ANTON PAAR, Austria) with a shear rate moving from 10 to $1000 \mathrm{~s}^{-1}$. Each measurement was repeated twice.

\section{Results and discussion}

\subsection{Chlorination temperature influence}

CDC film properties can be tuned starting from the same TiC thin film by changing the chlorination parameters such as temperature and time. The chlorination temperature affects the structural and textural properties [6,14], modulating the pore size distribution, BET surface area, disorder and mechanical strength, while the chlorination time mostly controls the film thickness [31]. Fig. 2A shows the Raman spectra of $450{ }^{\circ} \mathrm{C}$ and $700{ }^{\circ} \mathrm{C}$ partially chlorinated on-chip TiC-CDC samples. Whereas perfectly ordered graphite usually exhibits only one G-peak at $1580 \mathrm{~cm}^{-1}$, corresponding to in-plane stretching, the second D-peak at $1350 \mathrm{~cm}^{-1}$ is associated with disordered carbons. Here, D-band and G-band are clearly visible around $1340 \mathrm{~cm}^{-1}$ and $1590 \mathrm{~cm}^{-1}$, respectively, revealing the carbon is only partially graphitized for both $450{ }^{\circ} \mathrm{C}$ and $700{ }^{\circ} \mathrm{C}$ chlorination temperatures. No peaks are observed at low Raman shifts, confirming that titanium carbide layer was successfully converted into CDC [33]. Furthermore, as studied for SiC-CDC and $\mathrm{Mo}_{2} \mathrm{C}-\mathrm{CDC}$ [34], the deconvolution of the pics using a Gaussian-Lorentzian function evidences that the $\mathrm{I}_{\mathrm{D}} / \mathrm{I}_{\mathrm{G}}$ ratio changes while increasing the chlorination temperature, from 1.4 at $450{ }^{\circ} \mathrm{C}$ to 1.7 at $700{ }^{\circ} \mathrm{C}$, with a noticeable shift of the $\mathrm{G}$-peak from $1585 \mathrm{~cm}^{-1}$ to $1594 \mathrm{~cm}^{-1}$. This was also described for $\mathrm{Ti}_{3} \mathrm{SiC}_{2}$ ternary carbides [6]. As proposed by Ferrari and Robertson [35], the $I_{D} / I_{G}$ ratio is proportional to the square of the in-plane correlation length $L_{a}$ for more disordered carbons; aside, the 


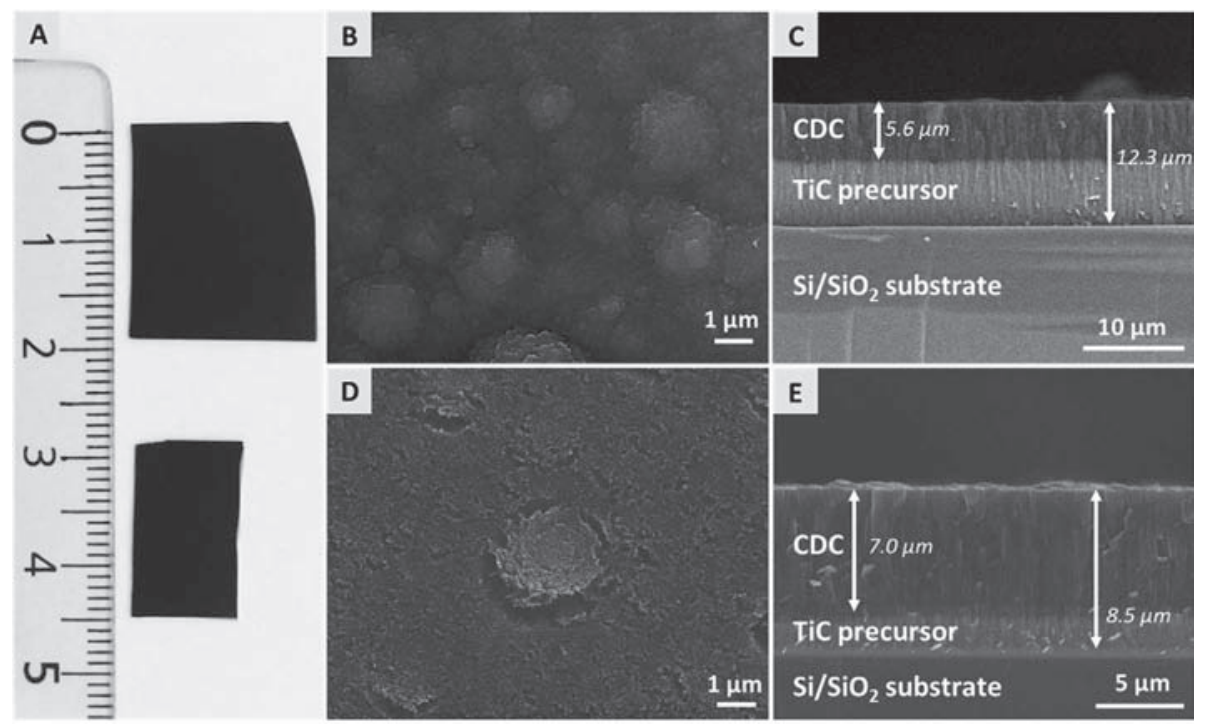

Fig. 1. Preparation of $\mathrm{CDC}$ films onto Si wafer. (A) Optical view of on-chip $\mathrm{CDC}$ films chlorinated at $450{ }^{\circ} \mathrm{C}$ (top) and $700{ }^{\circ} \mathrm{C}$ (bottom). (B) SEM images of a $450{ }^{\circ} \mathrm{C}$ chlorinated TiC-CDC surface and $(\mathrm{C})$ cross-section of the layered $\mathrm{Si} / \mathrm{SiO}_{2} / \mathrm{TiC} / \mathrm{CDC}$ obtained after partial chlorination of 5 min performed on a $12.3 \mu \mathrm{m}$-thick TiC film. (D) $\mathrm{SEM}$ images of a $700{ }^{\circ} \mathrm{C}$ chlorinated TiC-CDC surface and (E) cross-section of the $7.0 \mu \mathrm{m}$-thick CDC film obtained after partial chlorination of $2.5 \mathrm{~min}$ performed on an $8.5 \mu \mathrm{m}$-thick TiC film.

appearance of both pics in visible Raman spectra depends fundamentally on the ordering of $\mathrm{sp}^{2}$ sites and only weakly on the fraction of $\mathrm{sp}^{3}$ sites [35]. Therefore the increase of the $\mathrm{I}_{\mathrm{D}} / \mathrm{I}_{\mathrm{G}}$ ratio evidences to the progressive short-distance graphitization of the CDC film with increasing temperature, moving from an amorphous structure to an ordered carbon.

The chlorination time was extended $\left(20 \mathrm{~min}\right.$ at $450{ }^{\circ} \mathrm{C}$ and $5 \mathrm{~min}$ at $700{ }^{\circ} \mathrm{C}$ ) to fully convert the metal carbide precursor into CDC and separate the CDC film from the silicon substrate, as recently reported [31]. Fig 2B shows the pore volume and the pore size distribution of self-supported $\mathrm{CDC}$ films (using the $\mathrm{CO}_{2}$ gas sorption technique) fully chlorinated at $450{ }^{\circ} \mathrm{C}$ and $700{ }^{\circ} \mathrm{C}$. It gives Gaussian-like narrow pore size distributions with a mean pore size increasing from $0.59 \mathrm{~nm}$ to $0.85 \mathrm{~nm}$ while increasing the chlorination temperature. This is consistent with previous studies on CDC powders [11]. Besides, the pore size distribution is extended and reaches $2 \mathrm{~nm}$ diameters at $700{ }^{\circ} \mathrm{C}$, while no pores larger than $1 \mathrm{~nm}$ are found in the CDC structure prepared at $450{ }^{\circ} \mathrm{C}$. As an indication [36], the Brunauer-Emmett-Teller (BET) surfaces were calculated to be $977 \pm 30 \mathrm{~m}^{2} \mathrm{~g}^{-1}$ and $1026 \pm 30 \mathrm{~m}^{2} \mathrm{~g}^{-1}$ for the
$450{ }^{\circ} \mathrm{C}$ and $700{ }^{\circ} \mathrm{C}$ chlorinated self-supported CDC films, respectively.

Electrochemical characterizations of the on-chip TiC-CDC films partially chlorinated at $450{ }^{\circ} \mathrm{C}$ and $700{ }^{\circ} \mathrm{C}$ were achieved in $2 \mathrm{M}$ $\mathrm{EMIBF}_{4}$ in ACN from cyclic voltammetry at various scan rates, within a $3 \mathrm{~V}$ potential window. At $50 \mathrm{mV} \mathrm{s}^{-1}$ (Fig 2C), the current response was normalized to the footprint area of $C D C$ film. For the $450{ }^{\circ} \mathrm{C}$ TiC-CDC sample, a typical rectangular shape is observed between OCV (around $+0.4 \mathrm{~V}$ vs $\mathrm{Ag}$ ) and $+1.3 \mathrm{~V}$ vs $\mathrm{Ag}$, where the small $\mathrm{BF}_{4}^{-}$adsorption occurs. However, a sieving effect [37-39] can be seen between OCV and $-1.7 \mathrm{~V}$ vs Ag, with a distortion of the CV appearing. This distortion is associated with the limited accessibility of the larger $\mathrm{EMI}^{+}$to the pores (mean pore size of about $0.6 \mathrm{~nm}$ ), due to steric effects (bare cation size: $0.76 \mathrm{~nm}$ ) [27].

The $700{ }^{\circ} \mathrm{C}$ chlorinated TiC-CDC exhibits a typical capacitive signature within the entire voltage range of $3 \mathrm{~V}$, as expected from the increase of mean pore size $(1 \mathrm{~nm})$. Same observation was done on $800{ }^{\circ} \mathrm{C}$ chlorinated TiC-CDC powders tested in cavity microelectrode in 2M EMITFSI in ACN [40]. Here the pores can accommodate both the anions and the larger cations.
A

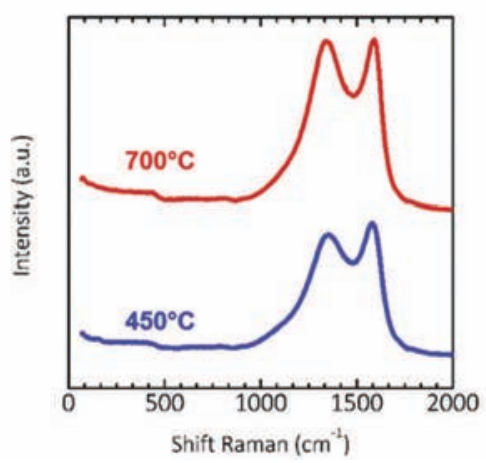

B

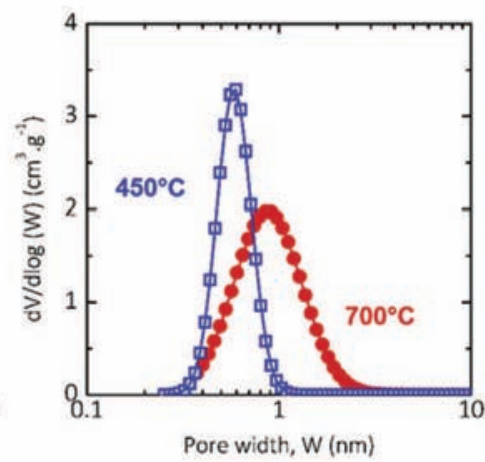

C

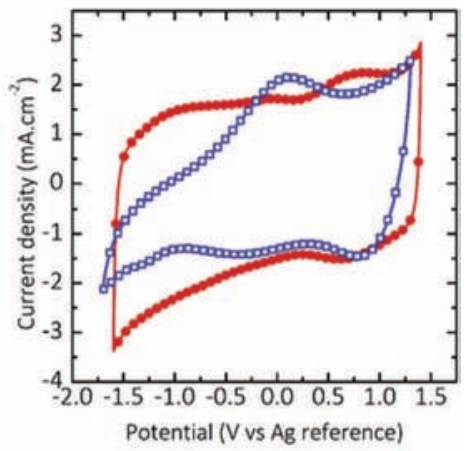

Fig. 2. Chlorination temperature influence. (A) Raman spectra of an on-chip CDC film chlorinated at $450{ }^{\circ} \mathrm{C}$ and $700{ }^{\circ} \mathrm{C}$. (B) Pore size distribution of the nanoporous self-supported $\mathrm{CDC}$ films chlorinated at $450{ }^{\circ} \mathrm{C}$ (open squares) and $700{ }^{\circ} \mathrm{C}$ (solid circles) established from $\mathrm{CO}_{2}$ gas sorption. $(\mathrm{C}) \mathrm{CVs}$ of a $\mathrm{Si} / \mathrm{SiO} \mathrm{O}_{2} / \mathrm{TiC} / \mathrm{CDC}$ electrode partially chlorinated at $450{ }^{\circ} \mathrm{C}$ (open squares) and $700{ }^{\circ} \mathrm{C}$ (solid circles) after annealing $1 \mathrm{~h}$ under $\mathrm{H}_{2}$ recorded in $2 \mathrm{M} \mathrm{EMIBF}_{4}$ in $\mathrm{ACN}$ at $50 \mathrm{mV} \mathrm{s}^{-1}$. 


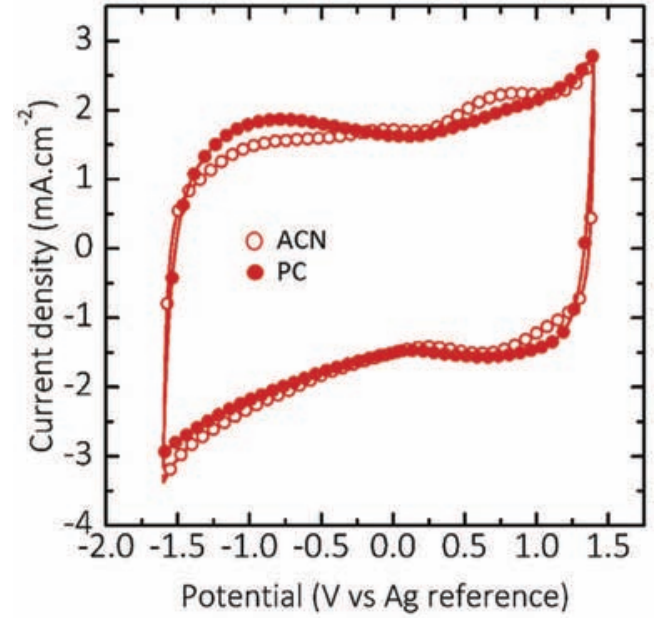

Fig. 3. Influence of the solvent of the electrolyte. CVs at $50 \mathrm{mV} \mathrm{s}^{-1}$ of a $2.1 \mu \mathrm{m}$-thick $\mathrm{CDC}$ electrode chlorinated at $700{ }^{\circ} \mathrm{C}$ and tested in $2 \mathrm{M} \mathrm{EMIBF}_{4}$ in $\mathrm{ACN}$ (open circles) and PC (solid circles).

\subsection{Influence of the solvent of the electrolyte}

As expected from similar study on ionic liquid-solvent mixture of $N$-butyl- $n$-methylpyrrolidinium bis(trifluoromethanesulfonyl) imide (PYR 14 TFSI) [41], the electrolyte viscosity was found to be higher in the IL-PC mixture than in the IL-ACN mixture, decreasing from $3.7 \mathrm{mPa}$ s to $0.4 \mathrm{mPa}$ s. Fig. 3 shows the cyclicvoltammograms of a Si/SiO $/ 2$ TiC/CDC electrode chlorinated at $700{ }^{\circ} \mathrm{C}$ for $30 \mathrm{~s}$ resulting in a $2.1 \mu \mathrm{m}$-thick $\mathrm{CDC}$ layer, recorded at $50 \mathrm{mV} \mathrm{s}^{-1}$ in both $2 \mathrm{M} \mathrm{EMIBF}_{4}$ in $\mathrm{ACN}$ and $2 \mathrm{M} \mathrm{EMIBF}_{4}$ in $\mathrm{PC}$ electrolytes. The current was normalized to the footprint area of electrode. Although both the electrolyte viscosity and resistivity are unfavorable when using $\mathrm{PC}$ as solvent $\left(3.7 \mathrm{mPa} \mathrm{s}\right.$ and $17 \mathrm{mS} \mathrm{cm} \mathrm{cm}^{-1}$ ), all CVs exhibit a rectangular shape characteristic of a capacitive signature within the whole potential window ( $3 \mathrm{~V}$ ) with similar capacitance. Indeed, the ions transfer kinetic into the porous carbon structure strongly depends on their diffusion coefficient, which is inversely proportional to the electrolyte viscosity. Then it can be estimated a characteristic distance $\delta$ along which the ions can accumulate on the material surface [42], given by (2):

A

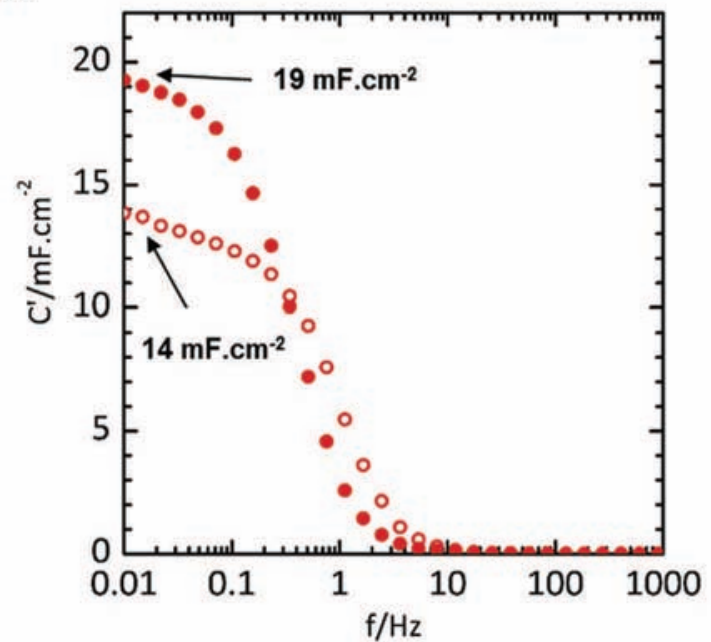

$$
\delta=\left(\frac{D \cdot R \cdot T}{F \cdot \nu}\right)^{0.5}
$$

where $D$ is the ions diffusion coefficient, $R$ is the ideal gas constant, $T$ is the temperature, $F$ is the Faraday constant and $\nu$ stands for the scan rate applied during the cyclic voltammetry. A rough estimation of the in-pore effective diffusion coefficient of the ions in $\mathrm{EMIBF}_{4}$ can be made assuming that its value is in the same order of magnitude than the one of similar $\mathrm{BMIPF}_{6}$ ions, i.e. $10^{-6} \mathrm{~cm}^{2} \mathrm{~s}^{-1}$ [43]. As a consequence, this distance becomes $7 \mu \mathrm{m}$ at $50 \mathrm{mV} \mathrm{s}^{-1}$. Here, the small thickness of the CDC films $(2.1 \mu \mathrm{m})$ ensures fast and efficient ion transport into the porous carbon network. A slight current decrease at the OCV is responsible for the small deviation from the ideal rectangular shape. Such a minimum capacitance at the OCV has already been reported for AC, OLC and graphene [44-46] and is attributed to a change of electronic density of states under polarization, allowing electrons to occupy higher energy states [46]. Areal capacitance of $35 \mathrm{mF} \mathrm{cm} \mathrm{m}^{-2}\left(168 \mathrm{~F} \mathrm{~cm}^{-3}\right)$ was delivered in both electrolytes, value in line with the volumetric capacitance reported in $\mathrm{NEt}_{4} \mathrm{BF}_{4} / \mathrm{ACN}$ [12].

From electrochemical impedance spectroscopy data, the frequency dependence of the electrode capacitance was analyzed using the complex capacitance model [47] where the capacitance is written as follows (3):

$$
C(\omega)=C^{\prime}(\omega)-j C^{\prime \prime}(\omega)
$$

The real $C^{\prime}(\omega)$ and imaginary $C^{\prime \prime}(\omega)$ parts of the capacitance are given by:

$$
\begin{aligned}
& C^{\prime}(\omega)=\frac{-Z^{\prime \prime}(\omega)}{\omega|Z(\omega)|^{2}} \\
& C^{\prime \prime}(\omega)=\frac{Z^{\prime}(\omega)}{\omega|Z(\omega)|^{2}}
\end{aligned}
$$

with $\omega$ the angular frequency, $Z^{\prime}(\omega)$ the real part and $Z^{\prime \prime}(\omega)$ the imaginary part of the impedance, and $|Z(\omega)|$ the impedance modulus. This model allows the qualitative study of the change of
B

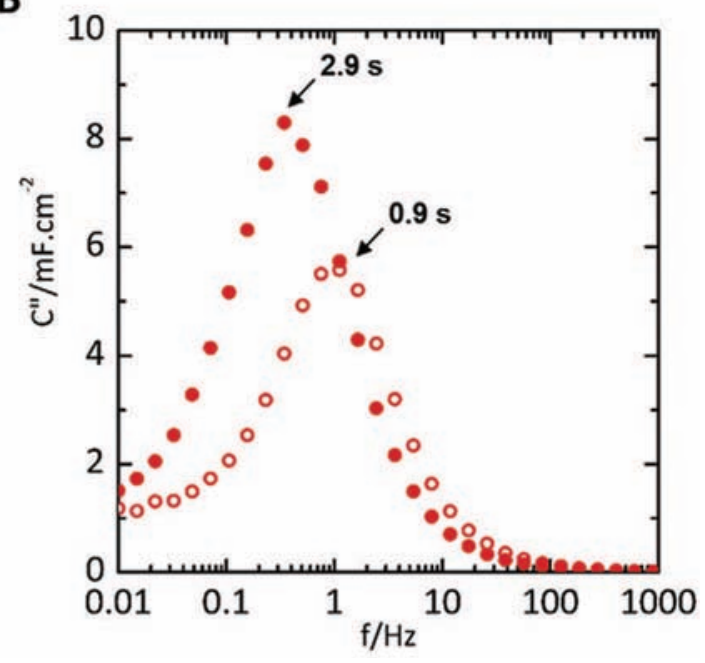

Fig. 4. (A) Change of the real and (B) imaginary parts of the capacitance vs frequency for a $2.1 \mu \mathrm{m}$-thick $\mathrm{CDC}$ electrode chlorinated at $700{ }^{\circ} \mathrm{C}$ and tested in $2 \mathrm{M}$ EMIBF $\mathrm{H}_{4}$ in $\mathrm{ACN}$ (open circles) and PC (solid circles). 


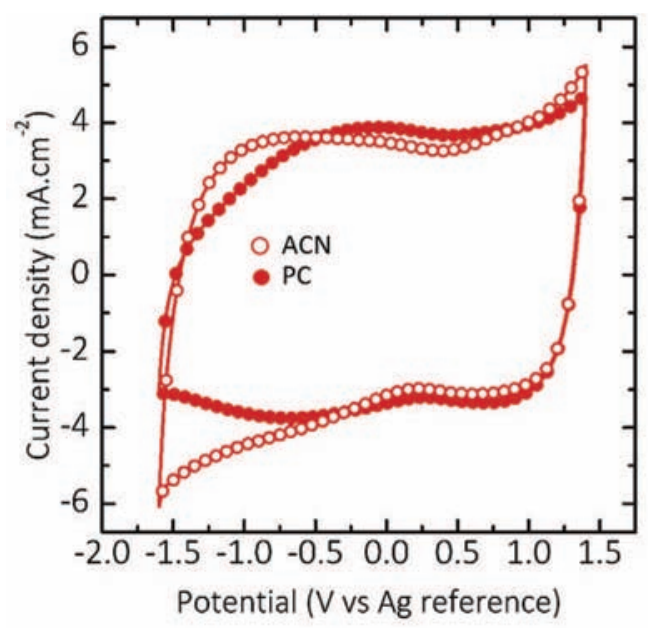

Fig. 5. Influence of the $\mathrm{CDC}$ thickness. $\mathrm{CVs}$ at $50 \mathrm{mV} \mathrm{s}^{-1}$ of a $7.0 \mu \mathrm{m}$-thick $\mathrm{CDC}$ electrode chlorinated at $700{ }^{\circ} \mathrm{C}$ tested in $2 \mathrm{M} \mathrm{EMIBF}_{4}$ in $\mathrm{ACN}$ (open circles) and PC (solid circles).

the capacitance with the frequency. Two parts are generally distinguished from $C^{\prime}$ vs frequency [47]. Capacitance change with frequency is linked to the interaction of carbon porosity and the electrolyte. At high frequency regime, only the carbon surface is accessible for ion adsorption; as a result, the electrode capacitance is low and it behaves like a pure resistance $(\phi \approx 0)$ [47]. Going down to low frequencies, the porous network becomes accessible to the ions so that the capacitance increases and reaches a plateau [47]. The change of the real part $C^{\prime}$ with frequency is presented on Fig. 4A. The two cells present capacitive plateaus in low frequency range, evidencing that the maximum capacitance of the electrode is reached. $C^{\prime}$ sharply increases from $9 \mathrm{~Hz}$ to $200 \mathrm{mHz}$ and tends to be less frequency dependent in ACN- than in PC-based electrolyte. Although ions can access the entire carbon porous network in both electrolytes, the difference in the low frequency behavior originates from the difference in electrolyte permittivity and viscosity, as reported before [47]. Fig. 4B plots the change of the imaginary part of the capacitance $C^{\prime \prime}$ vs frequency. $C^{\prime \prime}$ corresponds to an energy dissipation by an irreversible process that can lead to hysteresis, such as a dielectric loss in water [47]. The change of the imaginary part $C^{\prime \prime}$ with the frequency brings also additional information as it goes through a maximum value at a frequency $\mathrm{f}_{0}$, related to a time constant $\tau_{0}=1 / f_{0}$ [47]. The supercapacitors power ability strongly depends on this constant, giving the minimum time needed to achieve a discharge with an energy efficiency higher than $50 \%$. Here the time constants are similar in both electrolytes, namely $0.9 \mathrm{~s}$ and $2.9 \mathrm{~s}$ in $2 \mathrm{M} \mathrm{EMIBF}_{4}$ in $\mathrm{ACN}$ and PC, respectively. $\tau_{0}$ is defined at $\phi=-45^{\circ}$ and $C^{\prime}=C_{L F}^{\prime} / 2$ where $C_{L F}^{\prime}$ is the capacitance at low frequency. It can be seen on Fig. $4 \mathrm{~A}$ that half of the low frequency capacitance is reached at $\tau_{0}$.

The prepared on-chip micrometer-thick TiC-CDC film showed interesting performance in organic electrolytes, delivering a specific energy of $44 \mu \mathrm{Wh} \mathrm{cm} \mathrm{h}^{-2}\left(210 \mathrm{~mW} \mathrm{~h} \mathrm{~cm}^{-3}\right)$ and a specific power of $2.7 \mathrm{~mW} \mathrm{~cm}^{-2}\left(12.6 \mathrm{~W} \mathrm{~cm}^{-3}\right)$. These values challenge the CDC film performance in $1.5 \mathrm{NEt}_{4} \mathrm{BF}_{4} / \mathrm{ACN}$ [30].

\subsection{Influence of the $C D C$ film thickness}

CDC film thickness can be tuned with the chlorination time. Increasing the electrode thickness increases the areal capacitance, and provides better energy delivery, as long as the electrolyte resistance in the porous network (the ion transfer limitation) is kept low. Starting from a sputtered TiC thin film ( $8.5 \mu \mathrm{m}$-thick), on chip $7.0 \mu \mathrm{m}$-thick TiC-CDC were prepared by partial chlorination at $700{ }^{\circ} \mathrm{C}$ for 2 min 30 s. Samples were further annealed under $\mathrm{H}_{2}$ atmosphere at $600{ }^{\circ} \mathrm{C}$ for $1 \mathrm{~h}$ to remove trapped chlorine species [10].

Fig. 5 shows the CV curves of the $7.0 \mu \mathrm{m}$-thick CDC sample recorded at $50 \mathrm{mV} \mathrm{s}^{-1}$ in $2 \mathrm{M} \mathrm{EMIBF}_{4}$ in $\mathrm{PC}$ and ACN electrolytes. Capacitive signature is still observed in ACN based electrolyte within the whole potential window; the delivered capacitance is $72 \mathrm{mF} \mathrm{cm}^{-2}\left(103 \mathrm{~F} \mathrm{~cm}^{-3}\right)$ which is twice that of the previous capacitance obtained with thinner CDC layer. In the case of PCbased electrolyte, same rectangular shape can be seen between $\mathrm{OCV}(+0.4 \mathrm{~V}$ vs Ag$)$ and $+1.4 \mathrm{~V}$ vs Ag for anion adsorption. However, a distortion of the CV appears at negative potentials, leading to a capacitance decrease down to $65 \mathrm{mF} \mathrm{cm}^{-2}\left(92 \mathrm{~F} \mathrm{~cm}^{-3}\right)$. Same deviation from ideal rectangular shape has already been reported for $700{ }^{\circ} \mathrm{C}$ chlorinated TiC powders tested in $1.5 \mathrm{M} \mathrm{NEt}_{4} \mathrm{BF}_{4}$ in $\mathrm{ACN}$ [48]. The $\mathrm{CV}$ is not symmetrically distorted at positive potential values as it is expected for the ohmic drop in the bulk electrolyte, meaning that this distortion comes from a transport limitation of the $\mathrm{EMI}^{+}$
A

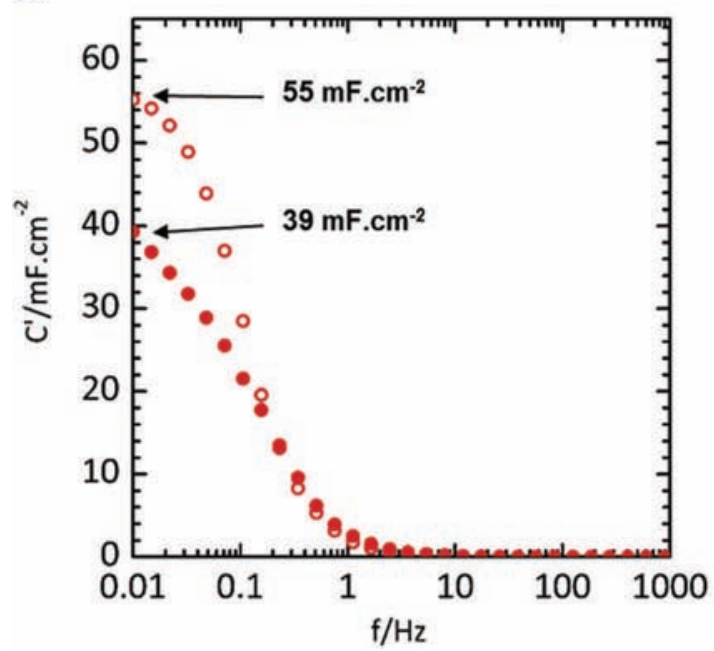

B

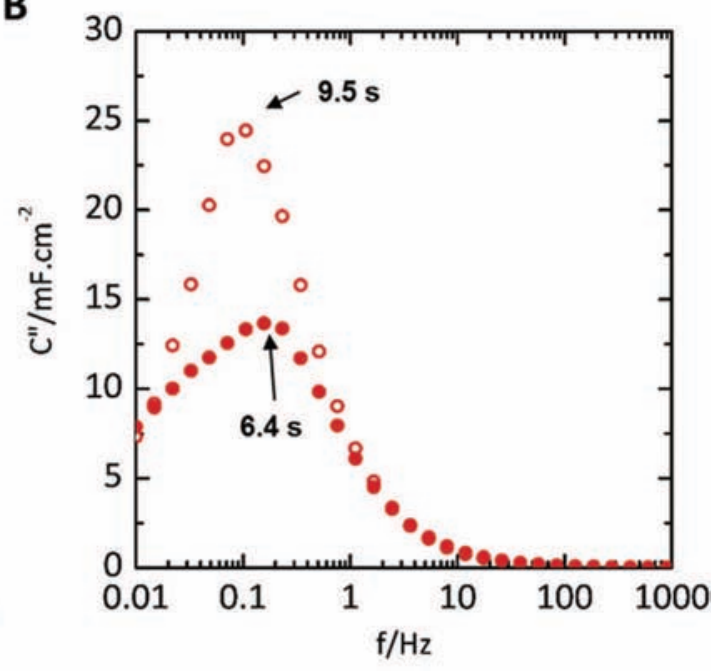

Fig. 6. (A) Change of the real and (B) imaginary parts of the capacitance vs frequency for a $7.0 \mu \mathrm{m}$-thick CDC electrode in $2 \mathrm{M}$ EMIBF 4 in $\mathrm{ACN}$ (open circles) and PC (solid circles). 
A

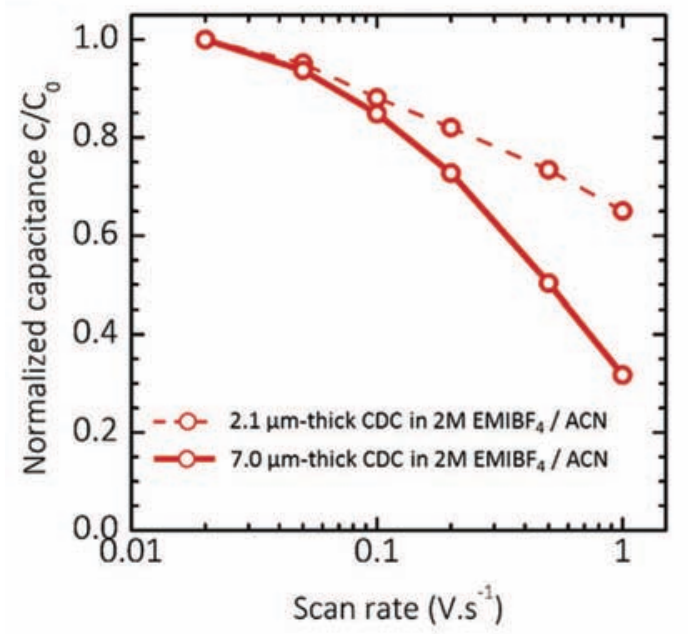

B

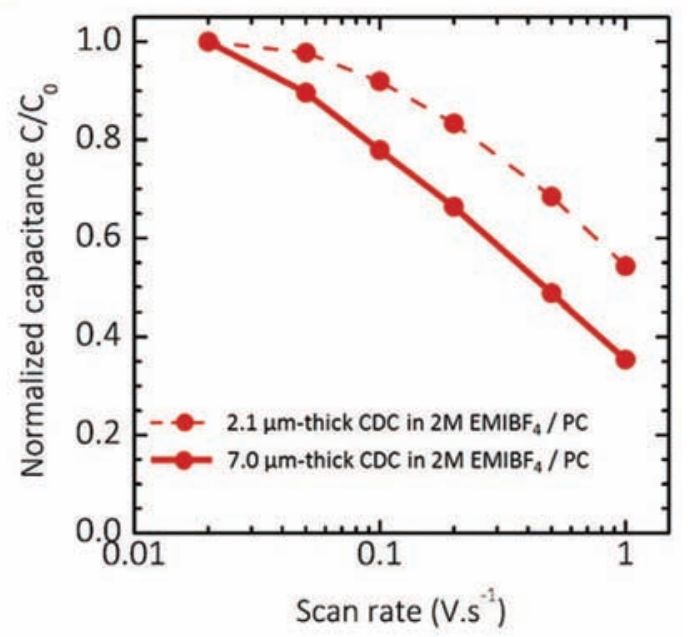

Fig. 7. Change of the capacitance with the scan rate for both $2.1 \mu \mathrm{m}$-thick (dashed line) and $7.0 \mu \mathrm{m}$-thick (solid line) CDC electrodes in (A) $2 \mathrm{M}$ EMIBF 4 in $\mathrm{ACN}$ (open circles) and (B) $2 \mathrm{M} \mathrm{EMIBF}_{4}$ in PC (solid circles).

cations in the porous network. In this thicker CDC layer, the electrolyte viscosity affects the mobility of the larger $\mathrm{EMI}^{+}$which cannot occupy the entire porosity. Furthermore, chlorine species removal by annealing under hydrogen may be less homogeneous in thicker CDC layer, leading to a reduced ion mobility in the whole film. As a consequence, the material performance are reduced for $7.0 \mu$ m-thick electrodes.

The change of the capacitance real part $C^{\prime}$ vs frequency is plotted in Fig. 6A. Differently from the $2.1 \mu \mathrm{m}$-thick CDC film, the capacitance of the $7.0 \mu \mathrm{m}$-thick film strongly depends on the frequency in both electrolytes. Because of the viscosity of the PC-based electrolyte, the capacitance is lower than that in ACN-based electrolyte in the whole frequency range. Aside, there is no evidence of the presence of a plateau at low frequency. Such features are explained, again, by the increase of the electrolyte resistance in the confined pores, in line with previous results [47]. The time constants $\tau_{0}$ measured at the maximum $\mathrm{C}^{\prime \prime}$ from Fig. $6 \mathrm{~B}$ is ten times higher $(9.5 \mathrm{~s})$ in $2 \mathrm{M} \mathrm{EMIBF}_{4}$ in $\mathrm{ACN}$ and twice higher (6.4 s) in $2 \mathrm{M} \mathrm{EMIBF}_{4}$ in PC than for a $2.1 \mu \mathrm{m}$-thick $\mathrm{CDC}$ film, reducing the $\mathrm{CDC}$ ability to fast charge and discharge.

The preparation of a $7.0 \mu \mathrm{m}$-thick CDC film at $700{ }^{\circ} \mathrm{C}$ with a mean pore size of $0.85 \mathrm{~nm}$ showed increased energy and power performance ( $90 \mu \mathrm{W} \mathrm{h} \mathrm{cm} \mathrm{cm}^{-2}$ and $5.3 \mathrm{~mW} \mathrm{~cm}^{-2}$ ) in ACN-based electrolyte. Moving from ACN to PC solvent comes with a decrease in energy and power performance $\left(81 \mu \mathrm{W} \mathrm{h} \mathrm{cm}{ }^{-2}\right.$ and $4.8 \mathrm{~mW} \mathrm{~cm}^{-2}$ ) because of increased electrolyte viscosity and resistivity.

To further investigate the influence of the CDC thickness on the performance of the as-prepared electrodes, cyclic voltammetry tests were achieved at several scan rates from $20 \mathrm{mV} \mathrm{s}^{-1}$ to $1 \mathrm{~V} \mathrm{~s}^{-1}$ in both ACN- and PC-based electrolytes. The capacitance was normalized to the maximum capacitance $\mathrm{C}_{0}$, and plotted vs scan rate (Fig. $7 \mathrm{~A}$ and $\mathrm{B}$ ). In $2 \mathrm{M} \mathrm{EMIBF}_{4}$ in $\mathrm{ACN}$, the $2.1 \mu \mathrm{m}$-thick CDC film retains more than $65 \%$ of the capacitance during a $3 \mathrm{~s}$ discharge $\left(1 \mathrm{~V} \mathrm{~s}^{-1}\right)$, while only $32 \%$ of $\mathrm{C}_{0}$ are still delivered for the $7.0 \mu \mathrm{m}$-thick CDC film. These results are in line with the change of the capacitance vs frequency presented in this study. Indeed, the real part $C^{\prime}$ is still on the low frequency plateau at $0.33 \mathrm{~Hz}$ for the $2.1 \mu \mathrm{m}$-thick CDC film, whereas it has already reached the high frequency regime for thicker CDC layer. Same observation was made in $2 \mathrm{M} \mathrm{EMIBF}_{4}$ in $\mathrm{PC}$, with $55 \%$ of the capacitance delivered at $1 \mathrm{~V} \mathrm{~s}^{-1}$ for the $2.1 \mu \mathrm{m}$-thick electrode to be compared with $35 \%$ for the $7.0 \mu$ m-thick electrode. It is noted as well that while the scan rate increases, the capacitance value decreases faster in more viscous PC-based electrolyte, which is in agreement with the higher frequency dependence observed for this sample (see Fig. 6). In addition, the capacitance value delivered by the as-prepared on-chip CDC films was stable over 1000 cycles in both electrolytes (Supplementary materials, Fig. S1 and S2). These performance make these on-chip prepared electrodes appealing for designing high energy and power delivery micro-supercapacitors.

\section{Conclusion}

Binder-free on-chip TiC-CDC films were produced by metallic atoms removal under chlorine atmosphere of sputtered TiC films on silicon wafer. Capacitive behavior within a $3 \mathrm{~V}$ potential range could be observed while tuning the pore size by increasing the chlorination temperature from $450{ }^{\circ} \mathrm{C}$ to $700{ }^{\circ} \mathrm{C}$. It allowed to investigate the behavior of $\mathrm{Si} / \mathrm{SiO}_{2} / \mathrm{TiC} / \mathrm{CDC}$ electrodes in $2 \mathrm{M}$ $\mathrm{EMIBF}_{4}$ diluted in either $\mathrm{ACN}$ or PC. Regarding previous studies in $1.5 \mathrm{M} \mathrm{NEt}_{4} \mathrm{BF}_{4} / \mathrm{ACN}$ and $1 \mathrm{M} \mathrm{NEt}_{4} \mathrm{BF}_{4} / \mathrm{PC}[38,47]$, thin TiC-CDC electrodes $(2.1 \mu \mathrm{m}$-thick) surprisingly showed no pore accessibility restrictions of $\mathrm{EMI}^{+}$and $\mathrm{BF}_{4}^{-}$while switching from $\mathrm{ACN}$ to PC solvent, and delivered $169 \mathrm{~F} \mathrm{~cm}^{-3}$ at $50 \mathrm{mV} \mathrm{s}^{-1}$ with good power capability ( $65 \%$ of the capacitance was still delivered at a scan rate of $1 \mathrm{~V} \mathrm{~s}^{-1}$ ). Expanding the CDC thickness up to $7 \mu \mathrm{m}$ brought more frequency dependency in both electrolytes and a transport limitation of the larger cations was observed in PCbased electrolyte. In spite of the relation between larger thickness and ion accessibility, a huge specific energy of $90 \mu \mathrm{W} \mathrm{h} \mathrm{cm}{ }^{-2}$ was recorded in $2 \mathrm{M} \mathrm{EMIBF}_{4}$ in $\mathrm{ACN}$, for a $5.3 \mathrm{~mW} \mathrm{~cm}^{-2}$ power density, thus challenging the best on-chip electrode materials [31].

\section{Acknowledgements}

K.B. was supported by the Chair of Excellence from the Airbus Group. P.H. was supported by the French Government [Agence Nationale de la Recherche (ANR) ASTRID program, MISE project]. P.S. acknowledges funding from the European Research Council (ERC Advanced Grant 2011 n²91543, “Ionaces”project). 


\section{Appendix A. Supplementary data}

Supplementary data related to this article can be found at http:// dx.doi.org/10.1016/j.jpowsour.2016.08.017

\section{References}

[1] P. Simon, Y. Gogotsi, Materials for electrochemical capacitors, Nat. Mater. 7 (2008) 845-854.

[2] T. Applications, http://www.maxwell.com/images/documents/datasheet_16v_ module.pdf, (accessed 30.05.16).

[3] J.R. Miller, A.F. Burke, Electrochemical capacitors: challenges and opportunities for real-world applications, Electrochem. Soc. 17 (2008) 53-57.

[4] P. Simon, Y. Gogotsi, Charge storage mechanism in nanoporous carbons and its consequence for electrical double layer capacitors, Philos. Trans. A Math. Phys. Eng. Sci. 368 (2010) 3457-3467.

[5] J. Miller, P. Simon, Electrochemical capacitors for energy management, Science 321 (2008) 651-652.

[6] Y. Gogotsi, A. Nikitin, H. Ye, W. Zhou, J.E. Fischer, B. Yi, H.C. Foley, M.W. Barsoum, Nanoporous carbide-derived carbon with tunable pore size, Nat. Mater. 2 (2003) 591-594.

[7] A. Erdemir, A. Kovalchenko, C. White, R. Zhu, A. Lee, M.J. McNallan, B. Carroll, Y. Gogotsi, Synthesis and tribology of carbide-derived carbon films, Int. J. Appl. Ceram. Technol. 3 (2006) 236-244.

[8] R. Dash, J. Chmiola, G. Yushin, Y. Gogotsi, G. Laudisio, J. Singer, J. Fischer, S. Kucheyev, Titanium carbide derived nanoporous carbon for energy-related applications, Carbon N. Y. 44 (2006) 2489-2497.

[9] S. Urbonaite, L. Hälldahl, G. Svensson, Raman spectroscopy studies of carbide derived carbons, Carbon N. Y. 46 (2008) 1942-1947.

[10] V. Presser, M. Heon, Y. Gogotsi, Carbide-derived carbons - from porous networks to nanotubes and graphene, Adv. Funct. Mater. 21 (2011) 810-833.

[11] C.R. Pérez, S.H. Yeon, J. Ségalini, V. Presser, P.L. Taberna, P. Simon, Y. Gogotsi, Structure and electrochemical performance of carbide-derived carbon nanopowders, Adv. Funct. Mater. 23 (2013) 1081-1089.

[12] J. Chmiola, C. Largeot, P.L. Taberna, P. Simon, Y. Gogotsi, Monolithic carbidederived carbon films for micro-supercapacitors, Science 328 (2010) 480-483.

[13] V. Presser, L. Zhang, J.J. Niu, J. McDonough, C. Perez, H. Fong, Y. Gogotsi, Flexible nano-felts of carbide-derived carbon with ultra-high power handling capability, Adv. Energy Mater. 1 (2011) 423-430.

[14] J. Chmiola, G. Yushin, Y. Gogotsi, C. Portet, P. Simon, P.L. Taberna, Anomalous increase in carbon capacitance at pore sizes less than 1 nanometer, Science 313 (2006) 1760-1763.

[15] J. Chmiola, G. Yushin, R. Dash, Y. Gogotsi, Effect of pore size and surface area of carbide derived carbons on specific capacitance, J. Power Sources 158 (2006) 765-772.

[16] W. Sugimoto, K. Yokoshima, Y. Murakami, Y. Takasu, Charge storage mechanism of nanostructured anhydrous and hydrous ruthenium-based oxides, Electrochim. Acta 52 (2006) 1742-1748.

[17] T. Brousse, P.L. Taberna, O. Crosnier, R. Dugas, P. Guillemet, Y. Scudeller Y. Zhou, F. Favier, D. Bélanger, P. Simon, Long-term cycling behavior of asymmetric activated carbon/ $\mathrm{MnO}_{2}$ aqueous electrochemical supercapacitor J. Power Sources 173 (2007) 633-641.

[18] V. Augustyn, P. Simon, B. Dunn, Pseudocapacitive oxide materials for high-rate electrochemical energy storage, Energy Environ. Sci. 7 (2014) 1597.

[19] F. Béguin, V. Presser, A. Balducci, E. Frackowiak, Carbons and electrolytes for advanced supercapacitors, Adv. Mater. 26 (2014) 2219-2251.

[20] A. Ferris, S. Garbarino, D. Guay, D. Pech, 3D RuO 2 microsupercapacitors with remarkable areal energy, Adv. Mater. 27 (2015) 6625-6629.

[21] B. Dyatkin, O. Gogotsi, B. Malinovskiy, Y. Zozulya, P. Simon, Y. Gogotsi, High capacitance of coarse-grained carbide derived carbon electrodes, J. Power Sources 306 (2016) 32-41.

[22] J. Leis, M. Arulepp, A. Kuura, M. Lätt, E. Lust, Electrical double-layer characteristics of novel carbide-derived carbon materials, Carbon N. Y. 44 (2006) 2122-2129.

[23] A. Jänes, E. Lust, Electrochemical characteristics of nanoporous carbidederived carbon materials in various nonaqueous electrolyte solutions, J. Electrochem. Soc. 153 (2006) A113-A116.

[24] H. Kurig, A. Jänes, E. Lust, Electrochemical characteristics of carbide-derived carbon/1-ethyl-3-methylimidazolium tetrafluoroborate supercapacitor cells, J. Electrochem. Soc. 157 (2010) A272-A279.

[25] J. Torop, V. Palmre, M. Arulepp, T. Sugino, K. Asaka, A. Aabloo, Flexible supercapacitor-like actuator with carbide-derived carbon electrodes, Carbon
N. Y. 49 (2011) 3113-3119.

[26] J. Segalini, E. Iwama, P.L. Taberna, Y. Gogotsi, P. Simon, Steric effects in adsorption of ions from mixed electrolytes into microporous carbon, Electrochem. Commun. 15 (2012) 63-65.

[27] C. Largeot, C. Portet, J. Chmiola, P.L. Taberna, Y. Gogotsi, P. Simon, Relation between the ion size and pore size for an electric double-layer capacitor, J. Am. Chem. Soc. 130 (2008) 2730-2731.

[28] E.N. Hoffman, G. Yushin, B.G. Wendler, M.W. Barsoum, Y. Gogotsi, Carbidederived carbon membrane, Mater. Chem. Phys. 112 (2008) 587-591.

[29] P. Huang, M. Heon, D. Pech, M. Brunet, P.L. Taberna, Y. Gogotsi, S. Lofland, J.D. Hettinger, P. Simon, Micro-supercapacitors from carbide derived carbon (CDC) films on silicon chips, J. Power Sources 225 (2013) 240-244.

[30] M. Heon, S. Lofland, J. Applegate, R. Nolte, E. Cortes, J.D. Hettinger, P.L. Taberna, P. Simon, P. Huang, M. Brunet, Y. Gogotsi, Continuous carbidederived carbon films with high volumetric capacitance, Energy Environ. Sci. 4 (2011) 135-138.

[31] P. Huang, C. Lethien, S. Pinaud, K. Brousse, R. Laloo, V. Turq, M. Respaud, A. Demortière, B. Daffos, P.L. Taberna, B. Chaudret, Y. Gogotsi, P. Simon, Onchip and freestanding elastic carbon films for micro-supercapacitors, Science 351 (2016) 691-695.

[32] T. Nishida, Y. Tashiro, M. Yamamoto, Physical and electrochemical properties of 1-alkyl-3-methylimidazolium tetrafluoroborate for electrolyte, J. Fluor Chem. 120 (2003) 135-141.

[33] B.H. Lohse, A. Calka, D. Wexler, Raman spectroscopy sheds new light on TiC formation during the controlled milling of titanium and carbon, J. Alloys Compd. 434-435 (2007) 405-409.

[34] H. Kurig, M. Russina, I. Tallo, M. Siebenbürger, T. Romann, E. Lust, The suitability of infinite slit-shaped pore model to describe the pores in highly porous carbon materials, Carbon N. Y. 100 (2016) 617-624.

[35] A. Ferrari, J. Robertson, Interpretation of Raman spectra of disordered and amorphous carbon, Phys. Rev. B 61 (2000) 14095-14107.

[36] M. Thommes, K. Kaneko, A.V. Neimark, J.P. Olivier, F. Rodriguez-Reinoso, J. Rouquerol, K.S.W. Sing, Physisorption of gases, with special reference to the evaluation of surface area and pore size distribution (IUPAC Technical Report), Pure Appl. Chem. 87 (2015) 1051-1069.

[37] L. Eliad, G. Salitra, A. Soffer, D. Aurbach, Ion sieving effects in the electrica double layer of porous carbon electrodes: estimating effective ion size in electrolytic solutions, J. Phys. Chem. B 105 (2001) 6880-6887.

[38] J. Segalini, B. Daffos, P.L. Taberna, Y. Gogotsi, P. Simon, Qualitative electrochemical impedance spectroscopy study of ion transport into sub-nanometer carbon pores in electrochemical double layer capacitor electrodes, Electrochim. Acta 55 (2010) 7489-7494.

[39] M.D. Levi, N. Levy, S. Sigalov, G. Salitra, D. Aurbach, J. Maier, Electrochemical quartz crystal microbalance (EQCM) studies of ions and solvents insertion into highly porous activated carbons, J. Am. Chem. Soc. 132 (2010) 13220-13222.

[40] R. Lin, P. Huang, J. Ségalini, C. Largeot, P.L. Taberna, J. Chmiola, Y. Gogotsi, P. Simon, Solvent effect on the ion adsorption from ionic liquid electrolyte into sub-nanometer carbon pores, Electrochim. Acta 54 (2009) 7025-7032.

[41] V. Ruiz, T. Huynh, S.R. Sivakkumar, A.G. Pandolfo, Ionic liquid-solvent mixtures as supercapacitor electrolytes for extreme temperature operation, RSC Adv. 2 (2012) 5591.

[42] E.J.F. Dickinson, R.G. Compton, Influence of the diffuse double layer on steadystate voltammetry, J. Electroanal. Chem. 661 (2011) 198-212.

[43] C. Pean, B. Daffos, B. Rotenberg, P. Levitz, M. Haefele, P.L. Taberna, P. Simon, M. Salanne, Confinement, desolvation, and electrosorption effects on the diffusion of ions in nanoporous carbon electrodes, J. Am. Chem. Soc. 137 (2015) 12627-12632.

[44] O. Barbieri, M. Hahn, A. Herzog, R. Kötz, Capacitance limits of high surface area activated carbons for double layer capacitors, Carbon N. Y. 43 (2005) 1303-1310.

[45] D. Weingarth, M. Zeiger, N. Jäckel, M. Aslan, G. Feng, V. Presser, Graphitization as a universal tool to tailor the potential-dependent capacitance of carbon supercapacitors, Adv. Energy Mater. 4 (2014) 1-13.

[46] C. Zhan, J. Neal, J. Wu, D.E. Jiang, Quantum effects on the capacitance of graphene-based electrodes, J. Phys. Chem. C 119 (2015) 22297-22303.

[47] P.L. Taberna, P. Simon, J.F. Fauvarque, Electrochemical characteristics and impedance spectroscopy studies of carbon-carbon supercapacitors, J. Electrochem. Soc. 150 (2003) A292.

[48] R. Lin, P. L. Taberna, J. Chmiola, D. Guay, Y Gogotsi, P. Simon, Microelectrode study of pore size, ion size, and solvent effects on the charge/discharge behavior of microporous carbons for electrical double-layer capacitors, J. Electrochem. Soc. 156 (2009) A7-A12 